\title{
24137 - EFFECTS OF CLONIDINE, TRAMADOL AND S(+)-KETAMINE AS ADJUVANTS IN BRACHIAL PLEXUS ANAESTHESIA USING ROPIVACAINE VERSUS LEVOBUPIVACAINE.
}

\author{
Francois Meurant MD, Emilie Colling, MD; Jo Welter, MD; Jean Pol Koch, \\ Michel Merle, Medical Professor \\ Kirchberg Hospital, Luxemburg, LUXEMBURG, Luxemburg
}

Introduction :The purpose of this study is (1)to compare the efficacy of the perivascular axillary Brachial Plexus (BP) approach using levo-bupivacaine $0.5 \%$ (Le) and ropivacaine $0.75 \%$ (Ro) using a nerve stimulator, (2) to study the effect of drug additives such as Clonidine (C), Tramadol (T) and $\mathrm{S}(+)$ - Ketamine (K), and finally (3) describe the post-operative analgesic effect of these three different additives.

Methods: We performed a prospective, randomized, double-blinded study including 325 ASA physical status I to III patients undergoing elective elbow and hand surgery after obtaining institutional agreement and patient consent. A short bevel needle ( $25 \mathrm{~mm} ; 22$ gauge; Stimuplex)) was introduced by the BP in order to obtain an appropriate Median (Me) and Musculo-Cutaneous (MC) nerve motor response at $<0.5 \mathrm{~mA}$ with a duration of $0.1 \mathrm{msec}$. Thereafter respectively $30 \mathrm{ml}$ in near the $\mathrm{M}$ and $10 \mathrm{ml}$ near in the $\mathrm{MC}$ of the different anaesthetic solutions were injected, determining 8 groups: $\mathrm{G} 1=\mathrm{Ro}(4 \mathrm{mg} / \mathrm{kg})($ $\mathrm{n}=50) ; \mathrm{G} 2=\mathrm{Ro}+\mathrm{C}(1.5 \mu / \mathrm{kg})(\mathrm{n}=50) ; \mathrm{G} 3=\mathrm{Ro}+\mathrm{T}(1.5 \mathrm{mg} / \mathrm{kg})(\mathrm{n}=50) ; \mathrm{G} 4=\mathrm{Ro}+\mathrm{K}(0.5 \mathrm{mg} / \mathrm{kg})$ $(\mathrm{n}=25) ; \mathrm{G} 5=\mathrm{Le}(3 \mathrm{mg} / \mathrm{kg})(\mathrm{n}=50) ; \mathrm{G} 6=\mathrm{Le}+\mathrm{C}(\mathrm{n}=50) ; \mathrm{G} 7=\mathrm{Le}+\mathrm{T}(\mathrm{n}=25) ; \mathrm{G} 8=\mathrm{Le}+\mathrm{K}(\mathrm{n}=25)$. Sensitive Onset(S.on) and Offset time(S.off) and Motor Onset (M.on) and Offset time (M.off) were measured. During the 10 hours following the S.off, a visual analogue scale was used and analgesic administration registered. Results are reported as median +/- SD. For statistical analysis a Shapiro-Wilk test, Wilcox and a Student T-test were used. Results: Whatever the adjunct drug used in the Le and Ro groups we noticed that the Radial nerve $(\mathrm{Ra})$ has slower S.on compared to the others (13.9+/-4.08min.) followed by the MC (12+/-3.78min.), the Cubital (Cu) (11.1+/-3.33min.) and the Me (11.1+/$3.18 \mathrm{~min})$. For all groups it was noticeable that $\mathrm{G} 2$ produced the more rapid S.on $(8+/-2$ $\min )(\mathrm{p}<0.0001)$; the longest M.off was obtained by G7(1226.4+/-108min) $(\mathrm{p}<0.0001)$ and the longest S.off was reached by G8 $(1200+/-54.4 \mathrm{~min})(\mathrm{p}<0.0001)$. Ketamine diminished the S.on in G4 (9.4+/-0.5min) as well as Clonidine in G2 when compared to G1 $(11+/-3 \mathrm{~min})(\mathrm{p}<0.0001)$ instead of K.-comportment on the S.off which was more significant $(\mathrm{p}<0.0001)$ in $\mathrm{G} 8$ when compared to all groups $(\mathrm{p}<0.0001)$. In Ro groups, analgesics demands were less in $\mathrm{G} 2(2 \%)$ than in G4(7\%) followed by G3(14\%). In the Le groups we found in G8 a 5\% demand when compared to G7 (7\%) and G6(9\%).

Conclusion: Adding drugs such as Tramadol, Clonidine (1) and S(+)-Ketamine to local anaesthetics has an effect in terms of Sensitive and Motor onset or offset times. Theses effects seems to be different if it's added with levobupivacaine or ropivacaine determining several pharmakodynamics different properties. It also decreases post analgesic requirements in brachial plexus anaesthesia.

References: 1 References: Ah El Saied, Steyn, Ansermino. Clonidine prolongs the effect of ropivacaine for axillary brachial plexus blockade. Can J Anaesth 2000;47:962-7 